\title{
O Museu Goeldi e a pesquisa arqueológica: um panorama dos últimos dezessete anos (1991-2008) ${ }^{1}$ \\ The Goeldi Museum and archaeological research: an overview of the past seventeen years (1991-2008)
}

Resumo: O texto apresenta um panorama da história recente (1991-2008) da Área de Arqueologia do Museu Paraense Emílio Goeldi, com as contribuições dadas por essa instituição para a arqueologia da Amazônia. Para compor esse panorama, foram consideradas as pesquisas realizadas, a formação de recursos humanos, os aspectos relacionados ao crescimento e à pesquisa do acervo sob a guarda da instituição e os aspectos infra-estruturais.

Palavras-chave: Arqueologia amazônica. Museu Paraense Emílio Goeldi. Acervo arqueológico.

Abstract: The paper presents an overview of the recent history (1991-2008) of the Archaeology Department in the Goeldi Museum (Museu Paraense Emílio Goeldi), with all its contributions for the archaeology of Amazonia. In order to assemble this overview, the research work undertaken, the formation of human resources, the various aspects related to the growth of and research on the collection housed in the institution, and infrastructural factors were all considered.

Keywords: Amazonian archaeology. Museu Paraense Emílio Goeldi. Archaeological collections.

1 Versão atualizada do trabalho apresentado durante o II Simpósio da Biota Amazônica, realizado pelo Museu Emílio Goeldi em Belém, de 11 a 14 de dezembro de 2006.

l Museu Paraense Emílio Goeldi. Coordenação de Ciências Humanas. Belém, Pará, Brasil (edithepereira@museu-goeldi.br).

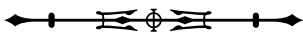


A avaliação dos primeiros cem anos de pesquisas arqueológicas na Amazônia foi o tema apresentado por Clifford Evans (1967) durante o Simpósio sobre a Biota Amazônica, realizado em 1966, em Belém. O autor apresentou o histórico dos trabalhos realizados na região, destacando as pesquisas desenvolvidas com Betty Meggers e mencionando a importância do Museu Emílio Goeldi no desenvolvimento das pesquisas arqueológicas na Amazônia.

Em 1981, Mário Simões (1981b) escreveu sobre o mesmo tema, particularmente sobre as pesquisas desenvolvidas pelo Museu Emílio Goeldi entre 1870 e 1981. De acordo com sua avaliação, esse longo período foi marcado por dois momentos: o Pioneiro (18701954) e o Atual (1955-1981). O primeiro se caracterizou pelas pesquisas exploratórias e pelas primeiras pesquisas acadêmicas. Algumas delas consistiram na colaboração com pesquisadores de instituições estrangeiras. $O$ período considerado como "atual" foi marcado pela estruturação do setor de Arqueologia do Museu Goeldi, pela formação de recursos humanos e pela execução de um conjunto de pesquisas arqueológicas coordenadas pelo próprio autor.

Dez anos depois, Barreto (1992) retoma o tema e apresenta a sua versão para a história da pesquisa arqueológica realizada pelo Museu Goeldi. Para isso, foi buscar, tal como Simões, desde as origens da pesquisa arqueológica no século XIX até o ano de 1991. Essa longa história foi dividida por Barreto em quatro períodos: Pioneiro (1866-1894), Goeldiano (1894-1907), Estacionário (19071948), Mário Simões (1962-1985) e Atual (1985-1991).

As origens do Museu Paraense Emílio Goeldi foi o tema de um livro publicado por Crispino, Bastos e Toledo em 2006. Uma análise minuciosa do contexto histórico no qual se desenvolveram as pesquisas realizadas por esse Museu entre a década de 1860 e 1907 foi desenvolvida por Sanjad (2005). Aspectos da história da pesquisa arqueológica realizada pelo Museu Goeldi estão presentes nessas obras e não poderia ser diferente, visto que a criação dessa instituição e o início da pesquisa arqueológica na Amazônia são indissociáveis.
As referências acima citadas se encarregam de apresentar, sob diferentes enfoques, a história da pesquisa arqueológica do Museu Goeldi para o período anterior a 1991. Decorridos mais de 15 anos desde a última atualização acerca da atuação da Área de Arqueologia do Museu Goeldi, é oportuno, nesse momento - quando se comemoram os 40 anos do I Simpósio da Biota Amazônica -, apresentar um quadro atualizado das pesquisas e das ações para a preservação do patrimônio arqueológico da Amazônia, realizadas pelo Museu Emílio Goeldi entre os anos de 1991 e 2008.

Esse período constitui um novo momento na história da pesquisa arqueológica, não apenas no Museu Emílio Goeldi, mas na Amazônia, na medida em que a instituição continua sendo o mais importante centro de pesquisa arqueológica da região. Essa importância está assentada não só nas pesquisas que realiza, mas também no seu quadro de pesquisadores e técnicos, na sua infra-estrutura e no acervo que mantém sob a sua guarda. Será com base nesses pilares que apresentarei as ações realizadas pela Área de Arqueologia do Museu Emílio Goeldi nos últimos 17 anos.

\section{PESQUISA}

Nos últimos anos, a Área de Arqueologia do Museu Emílio Goeldi realizou tanto pesquisas acadêmicas como pesquisas de contrato, além de colaborar constantemente com o Instituto do Patrimônio Histórico e Artístico Nacional (IPHAN).

As pesquisas acadêmicas, nesse período, foram marcadas pelo ineditismo, pela consolidação da linha de pesquisa voltada para a arqueologia histórica, pela retomada de pesquisas em áreas exploradas no século XIX, por pesquisas em regiões até então desconhecidas do ponto de vista arqueológico e pela parceria com pesquisadores de instituições estrangeiras.

A arte rupestre foi um tema deixado de lado durante décadas pelas pesquisas arqueológicas desenvolvidas na Amazônia. A partir de 1990, esses vestígios passaram a ser estudados de forma sistemática. Sua importância 
e presença em grande quantidade na região foram evidenciadas pelas pesquisas realizadas e que não permitem mais excluí-la da história pré-colonial da região. Mais de cem sítios com arte rupestre foram identificados somente no estado do Pará (Pereira, 2003). Outros duzentos sítios foram evidenciados nos demais estados da Amazônia Brasileira (Pereira, 1996). Os estudos realizados identificaram estilos próprios da região e deram visibilidade para esse tipo de registro, até então ausente no cenário arqueológico nacional e internacional.

As pesquisas de arqueologia histórica, iniciadas na década de 1980 (Barreto, 1992), são incrementadas na década de 1990 e se consolidam com a realização de uma série de projetos de pesquisa, dissertações de mestrado, teses de doutorado e diversos artigos científicos. Os engenhos movidos à maré (Marques, 1993, 2004, 2003a; Anderson e Marques, 1992; Anderson et al., 1992, 1993, 1996, 1997, 1999), as fortificações militares (Marques, 2006; Magalhães, 2006b), as construções religiosas (Marques, 2005b) e as missões religiosas da Amazônia (Lopes, 1999b) são alguns temas pesquisados. A história, na Amazônia, ganhou novos contornos revelados pelos dados oriundos das pesquisas arqueológicas.

Ao mesmo tempo em que a pesquisa arqueológica se aproxima de períodos mais recentes por meio do estudo de sítios históricos, ocorre também o inverso. Períodos muito antigos da ocupação humana passam a ser o foco de interesse de pesquisadores. Uma das datações mais antigas para a Amazônia - 8.000 A.P. - é proveniente da Serra de Carajás, região onde o Museu Goeldi conduziu, por vários anos, pesquisas arqueológicas (Simões, 1986; Magalhães, 1990, 1993, 1994a, 1994b, 1997, 2005, 2006a).

Cento e vinte anos após a descoberta da cerâmica da Cultura Maracá, feita por Francisco da Silva Castro e divulgada por Domingos Soares Ferreira Penna (1973), a região volta a ser foco de interesse do Museu Goeldi. Um projeto específico para a região do rio Maracá e Igarapé do Lago foi elaborado por Ana Machado e Mauro Barreto, e, posteriormente, executado por Guapindaia e Machado
(1997) entre 1994 e 2002. Por meio desse projeto, foram descobertos treze sítios-cemitérios com cento e cinqüenta urnas funerárias relacionadas à Cultura Maracá, cujo estudo permitiu conhecer as práticas funerárias desse povo (Guapindaia, 1999, 2000, 2001, 2008b; Souza et al., 2001; Santos et al., 1996).

No final da década de 1990, os sítios arqueológicos da ilha de Marajó - que já eram conhecidos e pesquisados desde o final do século XIX - voltam a ser foco de interesse da Área de Arqueologia do Museu Goeldi. Novos sítios são cadastrados e outros, já tantas vezes explorados, passam a ser pesquisados sob um novo olhar. Estudos sobre iconografia, gênero, organização social e práticas funerárias da cultura marajoara são o foco principal dessas pesquisas (Schaan, 2000a, 2000b, 2001a, 2001b, 2001c, 2003, 2004, 2005a, 2005b).

A costa atlântica do Pará foi uma das áreas pesquisadas pelo Museu Emílio Goeldi durante as décadas de 1970 e 1980 (Simões, 1981a; Corrêa, 1987). Os sambaquis dessa região voltam a despertar o interesse de pesquisadores da Área de Arqueologia, que estão preocupados em documentar novos sítios, dando um enfoque particular para a dieta alimentar dos grupos pescadores-coletorescaçadores que habitaram essa região (Gaspar e Imazio, 1999; Silveira e Schaan, 2005a, 2005b).

Se, por um lado, regiões como Maracá, Marajó e o litoral paraense já haviam sido exploradas anteriormente, muitas outras continuavam desconhecidas do ponto de vista arqueológico. Caxiuanã, Barcarena e Abaetetuba eram algumas delas.

A instalação de uma base física do Museu Emílio Goeldi na Floresta Nacional de Caxiuanã, nos municípios de Portel e Melgaço, propiciou a realização de um projeto que tinha por objetivo identificar a presença de sítios arqueológicos na área. $\bigcirc$ que efetivamente foi alcançado, sendo registrados três novos sítios, cujas características seguem o padrão predominante para os sítios amazônicos, com manchas de terra preta localizadas nas margens dos rios, porém com baixa densidade de material (Guapindaia et al., 1996). 
Em Barcarena e Abaetetuba, municípios localizados próximo a Belém, vinte novos sítios arqueológicos - históricos e pré-históricos - foram identificados em um projeto que tinha por objetivo caracterizar as potencialidades arqueológicas dessas áreas e contribuir para o conhecimento sobre os processos arqueológicos e históricos ocorridos na área do estuário amazônico. Além desses sítios, foram registradas quarenta e duas ocorrências e doze locais considerados como potenciais para a existência de sítio arqueológico (Silveira e Marques, 2004).

Ainda no âmbito da pesquisa acadêmica, destaca-se a parceria estabelecida com arqueólogos de instituições nacionais e estrangeiras no desenvolvimento de novas investigações. Entre esses últimos, foi importante a colaboração do Museu Emílio Goeldi nas pesquisas realizadas por Anna Roosevelt na ilha de Marajó (Roosevelt, 1991) e na região do Baixo Amazonas (Roosevelt et al., 1991, 1996), e por Michael Heckenberger no alto Xingu (Heckenberger, 2005; Heckenberger et al., 2008).

No Brasil, destacam-se os estudos interdisciplinares feitos em parceria com a Universidade Federal do Pará (UFPA) e com a Fundação Oswaldo Cruz (Fiocruz). A UFPA foi uma das instituições pioneiras na Amazônia na utilização de métodos geofísicos aplicados à arqueologia (Alves, 1979; Alves e Lourenço, 1981). A partir dessa experiência, diversos trabalhos utilizando esses métodos foram realizados com êxito através da parceria entre pesquisadores do Museu Goeldi e da UFPA (Roosevelt, 1991b; Pereira et al., 1986; Barradas et al., 1999; Bevan e Roosevelt, 2003; Luiz e Pereira, 2005; Aragão, 2006).

$\bigcirc$ estudo de restos esqueletais oriundos de sítios arqueológicos da Amazônia é o foco de uma frutífera parceria entre pesquisadores da UFPA, da Fiocruz e do Museu Emílio Goeldi. Destacam-se os trabalhos realizados na região de Maracá, no sul do Amapá (Santos et al. , 1996; Guapindaia, 2000; Souza et al., 2001) e em Canaã dos Carajás (Rodrigues-Carvalho, 2005; Souza, 2003).

O estudo dos restos faunísticos encontrados em sítios arqueológicos é feito no âmbito da zooarqueologia (ou arqueozoologia). Essa área do conhecimento também esteve presente nas pesquisas realizadas pelo Museu Goeldi nos últimos anos (Silveira, 1995, 2001).

Paralelamente às atividades voltadas para as pesquisas acadêmicas, registra-se o aumento considerável na demanda de trabalho que chega à instituição. Essa demanda tem sua origem tanto em órgãos governamentais, como o IPHAN, como em empresas (estatais e privadas) responsáveis por empreendimentos cuja implantação acarretará danos ao patrimônio arqueológico que, porventura, exista na área.

Nesse último caso, o aumento na demanda ocorreu por força da legislação brasileira, que condiciona o licenciamento de empreendimentos com determinadas características à realização de diversas pesquisas, entre as quais, a arqueológica. Conhecida como arqueologia de contrato, esse tipo de pesquisa visa identificar os sítios arqueológicos localizados nas áreas sob influência direta e indireta de determinado empreendimento e proceder ao seu salvamento, ou seja, pesquisar, produzir e difundir conhecimento sobre os sítios arqueológicos existentes nas áreas afetadas.

O Museu Emílio Goeldi, sendo a instituição de referência da pesquisa arqueológica na Amazônia, passou a ser procurado desde o final dos anos 1970 por diversas empresas para realizar esse tipo de pesquisa na região. A demanda foi grande na década 1980, diminuiu na primeira metade dos anos 1990 e voltou a crescer na segunda metade da década, dessa feita de maneira vertiginosa.

Trabalhos de levantamento para identificação do potencial arqueológico de determinadas áreas ou o salvamento de sítios que serão irremediavelmente destruídos passaram a fazer parte, juntamente com as pesquisas acadêmicas, da rotina de trabalho dos pesquisadores da Área de Arqueologia.

O Museu Goeldi foi uma das primeiras instituições do país a realizar pesquisa visando o salvamento de sítios arqueológicos. Preocupados com o destino de uma série de sambaquis e de outros sítios cerâmicos localizados no litoral paraense, Simões (1981a), Corrêa (1987) e Simões 
e Corrêa (1971) realizaram, na década de 1970, pesquisas em vários sítios dessa região.

Diversas pesquisas de contrato foram realizadas pela Área de Arqueologia do Museu Goeldi entre os anos de 1998 e 2008. Essas pesquisas possibilitaram a identificação de um grande número de sítios em áreas arqueologicamente já conhecidas, como o baixo curso do rio Xingu (Pereira, 2002b; Pereira e Guapindaia, 1999a), o rio Madeira (Magalhães, 2005c; Marques, 2005a), o rio Trombetas (Guapindaia, 2001), a região da Transamazônica (Magalhães, 2001, 2003) e o rio Tocantins (Guapindaia et al., 1998), e em outras, um pouco menos conhecidas, como o rio Capim (Magalhães, 2000) e o rio Oiapoque (Pereira e Guapindaia, 1999b).

Por meio desses projetos de contrato, foi possível descobrir muitos sítios situados em locais que dificilmente seriam percorridos ${ }^{2}$ se não fosse pela implantação de algum empreendimento, como são os casos daqueles instalados nos platôs e vales da região de Porto Trombetas, no noroeste do Pará (Guapindaia, 2008a), nas serras de Carajás (Magalhães, 1994a, 1994b, 2005), na área do Salobo (Silveira, 2007) e em Canaã dos Carajás (Pereira, 2008a), esses três últimos localizados no sudeste do Pará. O mesmo ocorreu em extensas áreas cortadas pela construção ou repavimentação de rodovias, como a Transamazônica (Magalhães, 2001, 2003; Schaan, 2005b; Schaan e Silva, 2005), a BR-163 (Schaan, 2006) e a Alça Viária de Belém (Magalhães, 2002a; Marques, 2002, 2003b), ou com a implantação de linhas de transmissão no Pará (Pereira, 2000; Magalhães, 2003, 2001; Guapindaia et al., 1998), no Acre (Schaan e Plens, 2005; Schaan, 2005c), no Amapá (Guapindaia et al., 2005) e em Rondônia (Bueno e Machado, 2005).

Em que pesem as críticas internas e externas que a Área de Arqueologia do Museu Emílio Goeldi sofre por realizar a chamada arqueologia de contrato, nenhum trabalho teria sido feito se não houvesse interesse na procura de respostas a questões acadêmicas ou para o conhecimento de áreas ainda inexploradas do ponto de vista arqueológico. Diferentemente de uma empresa de arqueologia, que atua em qualquer região do país, o Museu Goeldi só executa pesquisas de contrato em áreas dentro da Amazônia Brasileira, particularmente no estado do Pará, priorizando sempre áreas de seu interesse científico. A pesquisa de contrato possibilita a identificação e a investigação de diversos sítios, além dos dados e do material coletado ficarem acessíveis para outras pesquisas.

Atuando há mais de 140 anos na Amazônia, não é rara a coincidência entre o local onde um empreendimento vai ser executado com áreas onde o Museu Goeldi já tenha realizado pesquisas anteriormente. Nesses casos, são as informações das pesquisas realizadas por essa instituição que, muitas vezes, subsidiam Estudos de Impacto Ambiental (EIA) realizados por empresas de arqueologia. Alguns exemplos são os estudos de impacto ambiental das Usinas Hidrelétricas de Santa Isabel, no rio Araguaia, de Belo Monte, no rio Xingu, e de Tucuruí, no rio Tocantins.

Um reflexo da forma como a Área de Arqueologia do Museu Goeldi atua com relação aos projetos de contrato está na produção científica que foi gerada com base em informações obtidas por meio desses projetos. Em 2000, Caldarelli e Santos (2000) apresentaram um quadro da produção acadêmica da arqueologia de contrato no Brasil. Nele, a Amazônia é representada por apenas um artigo (Araújo Costa et al., 1988). No entanto, até 2000 , a produção científica do Museu Goeldi oriunda de projetos de contrato contava com uma tese de doutorado (Magalhães, 1999), duas dissertações de mestrado (Magalhães, 1990; Silveira, 1995), dois livros (Magalhães, 1994a, 1994b), dois artigos científicos (Simões, 1986; Magalhães, 1993) e duas publicações completas em anais de congresso (Magalhães, 1997, 1999).

A partir de 2000, a produção científica associada às pesquisas de contrato passa a contar com novas contribuições. Entre elas, destacam-se a publicação de

\footnotetext{
2 Pela total ausência de acesso e infra-estrutura, que só foram viabilizados em função da implantação de um determinado empreendimento.
}

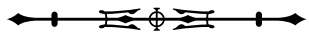


um livro (Magalhães, 2005a), a elaboração de uma tese de doutorado (Marques, 2004) e de uma dissertação de mestrado (Aragão, 2006), três capítulos de livro (Lima, 2006c; Pereira, 2008; Pereira et al., 2008a) e doze artigos publicados em anais de congressos (Magalhães, 2002b; Luiz e Pereira, 2005; Aragão et al., 2005; Lopes et al., 2006; Luiz et al., 2007a; 2007b; Ruivo et al., 2006; Oliveira et al., 2005; Lima, 2005; Lima e Machado, 2005; Lima e Pereira, 2007; Silveira et al., 2007). Muitos desses trabalhos têm sido apresentados em congressos nacionais e internacionais também na forma de painéis.

Além da produção acadêmica e dos relatórios, os projetos de contrato também possibilitaram a formação básica em arqueologia de diversos estudantes universitários que passaram a fazer estágio na Área de Arqueologia. Entusiasmados com a aproximação com a pesquisa arqueológica, muitos deles, além de auxiliar nas atividades dos projetos de contrato, utilizaram o tempo para produzir os seus trabalhos de final de curso ou de especialização, elegendo temas voltados para a arqueologia da Amazônia. Destacam-se os trabalhos de Barbosa (2001) sobre as urnas funerárias da região de Maracá (AP); de Martins (2005) sobre a cerâmica arqueológica da região de Caxiuanã (PA); de Silva (2002) sobre mudanças paisagísticas e os vestígios arquitetônicos remanescentes do final do século XVII em Santo Antônio do Gurupá (PA); de Fonseca Jr. (2004) sobre a história dos ídolos de pedra amazônicos; de Martins (2007a) sobre o material cerâmico do sítio Bitoca 2; e de Nascimento (2006) sobre as relações entre os arqueólogos e as comunidades.

Estudantes que ingressaram na Área de Arqueologia por meio de estágios e bolsas de iniciação científica também fizeram suas monografias de conclusão de curso com temas relacionados à arqueologia. Entre eles, estão os trabalhos de Rosa (2003, 2004) sobre a cerâmica tapajônica das coleções Townsend e Frederico Barata, pertencentes ao acervo do Museu Goeldi; de Ramos (2005) sobre as transformações urbanas e paisagísticas da antiga missão religiosa de Caiá, na ilha de Marajó; e de Cruz (2002) sobre peças lascadas de hematita provenientes da Serra Norte de Carajás.

Além das pesquisas de contrato, a Área de Arqueologia realizou diversos trabalhos de salvamento em sítios arqueológicos que, por razões diversas, estavam com a sua integridade comprometida. Em 1997, durante a abertura de uma vala para a implantação de canos para escoamento de água no campus da Fundação Universidade Federal do Amapá (UNIFAP), foi identificado um sítio arqueológico. O trabalho emergencial para salvaguardar o patrimônio encontrado foi realizado (Machado, 1997) e, em seguida, foi apresentado à UNIFAP, por solicitação da mesma, um projeto para dar continuidade à pesquisa no sítio. Apesar do interesse momentâneo demonstrado pelos dirigentes dessa universidade, o assunto não teve prosseguimento.

Em 1996, um sítio arqueológico localizado às margens do rio Novo, no município de Calçoene (AP), foi encontrado casualmente por um morador durante suas atividades de plantio. Tratava-se de um poço artificial contendo, em sua base, urnas funerárias da cultura Cunani. As intensas atividades agrícolas na área haviam comprometido seriamente o sítio arqueológico, restando apenas quatro urnas inteiras das onze que haviam sido encontradas (Coirolo, 1996).

No município de Melgaço (PA), sob a comunidade de Ilha de Terra, doze vasilhames arqueológicos afloravam à superfície e, a cada período de chuvas, sua integridade era comprometida. O salvamento desse patrimônio foi realizado entre os anos de 2003 e 2004 (Coirolo, 2004; Coirolo e D'Aquino, 2005).

Em 1999, um sítio arqueológico foi descoberto nas proximidades da cidade de Porto de Moz (PA), na área onde estava sendo implantada uma serraria. Todos os procedimentos legais para a realização do salvamento foram providenciados por parte do IPHAN e dos arqueólogos responsáveis (Pereira e Guapindaia, 1999a). No entanto, o proprietário do terreno onde estava o sítio não cumpriu a sua parte - custear a pesquisa -, o que impossibilitou a realização do salvamento. $\bigcirc$ 
caso foi encaminhado ao Ministério Público e, até hoje, desconhecemos o seu desfecho.

O caso de Porto de Moz remete a uma outra atividade constante da Área de Arqueologia do Museu Goeldi, a colaboração com o IPHAN. A carência de arqueólogos atinge também o órgão destinado a proteger o patrimônio arqueológico do país. Na falta desse profissional, a $2^{\text {a }}$ Superintendência Regional do IPHAN recorre constantemente ao Museu Goeldi, solicitando seus pesquisadores para realizar vistorias técnicas em sítios arqueológicos nos estados do Pará e Amapá, área de abrangência daquela Superintendência. Tratam-se, via de regra, de denúncias sobre saque e destruição de sítios arqueológicos ou de informações sobre a existência de sítios, acompanhadas de pedidos para a realização de pesquisas.

Nos últimos anos, várias denúncias têm sido feitas como conseqüência do diálogo entre os arqueólogos e as comunidades, e dos projetos de educação patrimonial realizados pelo Museu Goeldi. A expectativa criada pelos denunciantes, algumas vezes, acaba sendo frustrada, na medida em que nem sempre a vistoria pode ser realizada de forma imediata ou a pesquisa realizada após a vistoria.

Atualmente, estão sendo realizadas, pelo menos, duas ações do IPHAN em parceria com o Museu Goeldi, ambas motivadas por denúncias de moradores das comunidades sobre a destruição e o vandalismo nos sítios. Uma delas é na Vila de Joanes, ilha de Marajó, cujas ações estão voltadas para a preservação, conservação, pesquisa e educação patrimonial no sítio histórico de Joanes, uma missão religiosa fundada no século XVII (Marques e Schaan, 2006). A outra ação está sendo realizada no Distrito do Pacoval do Curuá, em Prainha (PA), e tem como foco a pesquisa arqueológica, a educação patrimonial e o turismo sustentável na região (Pereira et al., 2008b).

A colaboração com o IPHAN não se resume a vistorias técnicas em sítios arqueológicos. $\bigcirc$ Museu Goeldi também tem colaborado, constantemente, com esse instituto, fornecendo informações sobre os sítios arqueológicos da Amazônia, para alimentar a base de dados do Cadastro Nacional de Sítios Arqueológicos (CNSA). Informações constantes nessa base estão disponibilizadas na internet, no site do IPHAN, para consulta pública.

\section{EDUCAÇÃO PATRIMONIAL}

As relações que se estabelecem entre os pesquisadores e as comunidades das áreas onde são feitas as investigações arqueológicas constituem um tema que só recentemente passou a merecer a atenção por parte tanto de pesquisadores como dos órgãos gestores do patrimônio cultural.

O Museu Goeldi foi uma das instituições pioneiras a apresentar, ainda na década de 1980, uma reflexão sobre as relações entre os arqueólogos e as populações ribeirinhas. Esse trabalho foi baseado na experiência de um grupo de jovens pesquisadores que participou de um projeto de contrato realizado entre 1986 e 1988 no baixo curso do rio Xingu (Oliveira et al., 1988). Entre as conclusões apresentadas nesse trabalho, consta a recomendação para incluir, nos projetos arqueológicos, ações no sentido de informar adequadamente as comunidades sobre o significado do trabalho do arqueólogo e, com isso, promover a sua aproximação com a pesquisa. Ao conhecer a importância da pesquisa, a preservação do patrimônio arqueológico viria como uma conseqüência natural.

Com vistas à interação construtiva entre os arqueólogos e o público - particularmente entre as comunidades que vivem próximas às áreas afetadas por empreendimentos cuja construção e operação provocam alterações ambientais e patrimoniais - o IPHAN determinou, através da Portaria ${ }^{\circ}$ 230, de 17 de dezembro de 2002, a necessidade de realização de programas de educação patrimonial em todas as fases do licenciamento ambiental dos empreendimentos.

Em 2001, antes da publicação da referida Portaria, a Área de Arqueologia do Museu Goeldi deu início ao primeiro trabalho de educação patrimonial vinculado a um projeto de pesquisa de contrato na Amazônia. Esse trabalho vem sendo realizado no município de Oriximiná 
(PA), na região de Porto Trombetas, e beneficia quatro comunidades. Crianças, adolescentes e adultos participam das atividades do projeto, que incentiva a leitura e a pesquisa, estimula atividades empreendedoras por meio da produção de artesanato e valoriza os ceramistas locais. O projeto já produziu um vídeo e uma série de jogos educativos, cartilhas e exposições itinerantes.

Nos anos seguintes, tiveram início três outros projetos de educação patrimonial vinculados a projetos de contrato, abrangendo os municípios de Canaã dos Carajás ${ }^{3}, M_{0 j u}^{4}$, Abaetetuba $^{5}$ e Parauapebas 6 , todos no Pará. Por meio desses projetos, foram elaboradas várias mídias pedagógicas com o objetivo de atender às diversas faixas etárias das comunidades existentes no entorno do empreendimento. Assim, foram elaboradas duas revistas com histórias em quadrinhos (Cunha et al., 2004; Cruz et al., 2004), três vídeos (Figueiredo, 2005, 2006, 2007), um livro (Lima, 2003) e sete cartilhas de leitura e exercícios (Leal, 2005; Atikun, 2005; Lima, 2005a, 2005b, 2006a, 2006b; Soeiro et al., 2008).

Os dois projetos pioneiros voltados para educação patrimonial, realizados nos municípios de Oriximiná e Canaã dos Carajás, renderam frutos importantes para os participantes. Em ambos, o objetivo maior foi alcançado, que é a valorização da memória cultural dos antepassados evidenciada nas formas e na decoração da cerâmica arqueológica.

Em Canaã dos Carajás, o projeto de educação patrimonial envolveu quatro comunidades situadas no entorno de uma mina de cobre. Além da valorização do patrimônio arqueológico, o projeto atingiu outros objetivos, como a multiplicação do conhecimento por parte dos professores locais e também de crianças e adolescentes, e o desenvolvimento sustentável dessas comunidades (Lima e Pereira, 2007).

\section{RECURSOS HUMANOS}

Uma das mudanças mais marcantes ocorridas nos últimos anos está relacionada com a drástica redução no número de pesquisadores atuando na Área de Arqueologia ${ }^{7}$. Essa redução foi ocasionada por aposentadorias, transferências para outros departamentos dentro da instituição e para outras instituições. O quadro de pesquisadores, que em 1991 era de treze arqueólogos, foi reduzido, em 1998, para seis e, em 2004, para cinco, o que significa uma redução de mais de $60 \%$. Se, por um lado, houve a diminuição no número de pesquisadores, por outro, registra-se o retorno à instituição daqueles que haviam saído para cursar pós-graduação.

A capacitação profissional dos funcionários, aliada à presença de pesquisadores bolsistas, trouxe novo fôlego para a Área de Arqueologia. Novos projetos acadêmicos começaram a ser desenvolvidos, alguns abordando temas até então pouco ou nada explorados pelas pesquisas anteriores, como são os casos da arqueologia histórica e da arte rupestre.

Acompanhando esse novo cenário, registra-se a aproximação de um número importante de alunos universitários interessados na pesquisa arqueológica. Se, por um lado, isso se configura como um estímulo, por outro, esbarra em um cenário desanimador, marcado pela ausência de cursos de graduação e pós-graduação (strictu e lato sensu) em arqueologia na região Norte e pela distância geográfica da Amazônia em relação aos centros de formação de arqueólogos no país.

Visando suprir um pouco dessa carência, estabeleceuse como metas a serem alcançadas a formação de recursos humanos e o fortalecimento da Área de Arqueologia por meio de pesquisadores visitantes. Apesar de tradicionalmente atuar na realização de pesquisas arqueológicas, essa Área foi a responsável pela formação

3 Programa de Arqueologia Preventiva na Área da Mineração Serra do Sossego.

${ }^{4}$ Programa de Arqueologia Preventiva na Área do Projeto Bauxita-Paragominas e Programa de salvamento e monitoramento de sítios arqueológicos no traçado da Alça Rodoviária - Belém/PA.

5 Programa de Arqueologia Preventiva na Área do Projeto Bauxita-Paragominas.

6 Projeto de Salvamento Arqueológico na Área do Salobo (Carajás).

Os números correspondem apenas aos funcionários efetivos do Museu Goeldi.

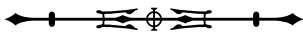


básica de vários profissionais que atuam hoje na região. A partir de 1992, quando o Programa Institucional de Bolsas de Iniciação Científica foi implantado no Museu Goeldi, com o apoio do Conselho Nacional de Desenvolvimento Científico e Tecnológico (CNPq), a formação de estudantes ficou vinculada, principalmente, a esse programa. Quanto aos pesquisadores visitantes, cerca de vinte atuaram na Área de Arqueologia por meio de bolsas de pesquisa do CNPq ou de projetos de contrato.

Dando continuidade a esse processo e visando a reciclagem de técnicos e profissionais que atuavam tanto no Pará como em outros estados da Amazônia, a Área de Arqueologia promoveu, em 1997, o curso "Prática em Arqueologia Amazônica". Ministrado pelo Dr. Michael Heckenberger, o curso constou de aulas teóricas e de prática de campo. Teve como público profissionais de diversas instituições do Pará, Amapá e Amazonas, além de contar com a participação de estudantes de pós-graduação da Universidade de São Paulo e da Pontifícia Universidade Católica do Rio Grande do Sul (Pereira, 1998).

Apesar do esforço que o Museu Goeldi tem despendido para a formação de pessoal, seja por meio de cursos de curta duração ou de estágios, ainda é fundamental para a região Norte a implantação de um curso de pós-graduação strictu sensu em arqueologia. A região amazônica tem um potencial arqueológico proporcional à sua dimensão geográfica, e não há arqueólogos suficientes fixados na região para atender a demanda de trabalho.

Ao longo desses dezessete anos, observou-se que um dos motivos que desestimulam os estudantes a seguir a carreira de arqueólogo é a falta de perspectiva de absorção de novos profissionais por centros de pesquisa e universidades. Essa situação, aliada à enorme demanda de trabalho oriunda de empreendimentos que, por força da lei, são obrigados a realizar pesquisa arqueológica para a obtenção de licenças ambientais, estimulou a criação de diversas empresas especializadas em pesquisa arqueológica de contrato.
Atualmente, um grande número de arqueólogos autônomos, estudantes de pós-graduação e até mesmo alunos em formação tem sido recrutado para trabalhar para essas empresas. Essa situação, ainda que rentável, proporciona pouco incentivo à produção de conhecimento, restringe a crítica social (Funari, 2003) e limita a atuação do profissional a atender (enquanto houver) a demanda por esse tipo de trabalho.

Há seis anos, Caldarelli e Santos (2000) consideravam que as universidades eram as grandes preferidas na contratação para a execução de programas de resgate pelas condições que ofereciam para a análise, guarda e curadoria do material coletado. De acordo com a sua avaliação, esse quadro começava a mudar face à crescente contratação de empresas especializadas nesse tipo de serviço, que passavam a contar com o apoio das universidades.

Atualmente, essa é a situação que parece predominar no país. Cada vez mais empreendedores deixam de lado universidades e centros de pesquisa regionais - antes responsáveis pelas pesquisas - e passam a procurar empresas de arqueologia - a maioria sediada no Sul e Sudeste do país - para realizar pesquisas em todo o território nacional com o objetivo de obter licenciamentos. A pesquisa arqueológica passou a ser, do ponto de vista das empresas, uma atividade muito melhor de ser negociada entre duas empresas - a do empreendedor e a do arqueólogo-empresário - do que com os centros de pesquisa.

\section{INFRA-ESTRUTURA E ACERVO}

Em 1996, a Coordenação de Ciências Humanas do Museu Goeldi teve a sua base física transferida do Parque Zoobotânico - local de suas antigas instalações - para - Campus de Pesquisa do Museu Goeldi. As novas instalações foram construídas visando dar melhor infraestrutura para os pesquisadores e para o acervo. Além de salas para pesquisadores, técnicos e bolsistas, a Área de Arqueologia conta hoje com três laboratórios projetados para análise de material arqueológico, um laboratório para 
restauração e um amplo salão para guarda provisória e processamento inicial do material a ser analisado.

Em 1997, o acervo arqueológico foi transferido para o novo prédio, projetado especificamente para receber esse tipo de acervo. O local recebeu o nome de Reserva Técnica "Mário Ferreira Simões" em homenagem à contribuição dada por esse pesquisador para a arqueologia da Amazônia (Museu Paraense Emílio Goeldi, 2002). Com 360 m²$^{2}$, abriga todo o acervo arqueológico do Museu Goeldi. Esse novo espaço foi preparado visando dar condições ideais de acondicionamento e segurança ao acervo, cuja formação data do século XIX.

Para o acondicionamento do material arqueológico, são usadas caixas e bandejas de polietileno, organizadas em estantes em chapa de aço, um material de forte resistência a ataques de insetos e micro-organismos. O espaço da reserva técnica é climatizado, com temperaturas entre $18^{\circ}$ e $21^{\circ} \mathrm{C}$ e umidade relativa entre $55 \%$ e $65 \%$, para melhor conservação do acervo. 0 controle desse ambiente é monitorado por meio de desumidificadores, termohigrômetros e termohigrográfos (Museu Paraense Emílio Goeldi, 2002).

Com o acervo reunido em um só espaço, teve início um projeto cujos objetivos são a reorganização e a documentação das coleções. Esse projeto visa não apenas o acondicionamento do acervo no novo espaço, mas também a reformulação do sistema de gestão e documentação. $\bigcirc$ registro do acervo arqueológico era feito, anteriormente, de forma manual em livros e fichas criados para esse fim. Hoje, o sistema é informatizado, permitindo acesso rápido e fácil às peças e às informações sobre elas.

No âmbito desse projeto, tem sido estimulado o estudo científico de coleções arqueológicas do Museu Goeldi. Muitas coleções que compõem o acervo foram formadas no final do século XIX e no início do século $X X$, sem que houvesse grande preocupação do coletor em sistematizar a coleta ou contextualizar as peças. No entanto, trata-se de um material importante, muitas vezes representativo de áreas pouco (ou nada) conhecidas do ponto de vista arqueológico, que quando devidamente estudado ganha significado científico, tornando-se uma nova fonte de informação. $\bigcirc$ estudo das coleções arqueológicas tem privilegiado não apenas o acervo em si, mas também o seu colecionador.

Dentre os estudos realizados com as coleções do acervo arqueológico do Museu Goeldi, destacam-se as contribuições de Guapindaia (1993) sobre os Tapajó, realizado a partir da coleção cerâmica formada por Frederico Barata; de Rosa (2003) sobre as coleções de cerâmica tapajônica formadas por Charles Townsend e Frederico Barata; de D`Aquino $(2001,2003)$ sobre os cachimbos cerâmicos de Alenquer e Santarém; de Fonseca Jr. (2004) sobre os ídolos de pedra; e de Martins (2007b) sobre a coleções formadas por Protásio Frikel.

acervo arqueológico do Museu Goeldi vem crescendo continuamente ao longo dos anos, seja por meio de pesquisas acadêmicas, de contrato ou doações. Atualmente, o acervo da instituição ultrapassa dois milhões de itens, entre fragmentos, peças inteiras e semi-inteiras. Algumas das mais importantes coleções arqueológicas da Amazônia estão sob a guarda do Museu Goeldi. Entre elas, destacam-se a coleção de peças Cunani, formada por Emílio Goeldi e Aureliano Lima Guedes, em 1895; a coleção de peças Maracá formada por Aureliano Lima Guedes, em 1896; a coleção de peças Santarém formada por Frederico Barata, Curt Nimuendaju e Townsend; a coleção de peças do Marajó formada por Betty Meggers; e as coleções formadas por Protásio Frikel em diversas regiões do Pará, em particular aquelas provenientes dos rios Paru de Leste, Paru de Oeste, Serra do Tumucumaque e rio Itacaiúnas.

O acervo arqueológico do Museu Goeldi, constituído fundamentalmente por artefatos cerâmicos e líticos, contém peças representativas dos diversos povos indígenas que viveram na Amazônia antes e no momento do contato com o colonizador europeu. Essas peças têm sido apresentadas ao público em diversas exposições realizadas em Belém, 
em outros estados do Brasil e em diversos países. Entre os anos 1998 e 2008, foram realizadas 17 exposições em cinco países e em cinco estados brasileiros.

O acervo conta, ainda, com uma coleção osteológica proveniente de diversos sítios da Amazônia, que também é objeto de estudo. Entre os trabalhos realizados com esse acervo, destacam-se a análise feita por Sabá (2000) sobre os restos esqueletais oriundos das urnas funerárias de Maracá, no Amapá, e o estudo feito por Queiróz (2001) para os restos faunísticos das Grutas do Gavião e do Pequiá, localizadas na região de Carajás, no Pará.

Atualmente, parte do acervo osteológico da Área de Arqueologia do Museu Goeldi está sendo analisado por dois projetos relacionados com o estudo de restos humanos provenientes de sítios arqueológicos. Trata-se dos projetos "Paleogenética e paleoepidemiologia em populações pré-históricas da Amazônia" e "Diversidade Morfológica Craniana, Microevolução e Ocupação PréHistórica da Costa Brasileira". O primeiro é desenvolvido em parceria com o Laboratório de Genética Humana do Departamento de Patologia da Universidade Federal do Pará, sob a coordenação da Dra. Ândrea Santos, e visa associar os estudos de restos humanos provenientes de sítios arqueológicos da Amazônia com estudos sobre o DNA antigo encontrado em tais materiais. A finalidade desse projeto é a busca de dados que possam auxiliar no entendimento sobre a vida de nossos antepassados.

O segundo projeto é coordenado pelo Dr. Walter Neves e por Mercedes Okumura, do Laboratório de Estudos Evolutivos Humanos do Departamento de Biologia da Universidade de São Paulo, e tem por objetivo testar hipóteses relativas à diversidade morfológica de crânios oriundos dos sambaquis do litoral brasileiro.

\section{PRÊMIOS}

Ao longo dos últimos anos, o trabalho desenvolvido pela Área de Arqueologia tem merecido reconhecimento nacional, seja por meio de premiações ou pela sua classificação entre os finalistas de importantes prêmios.
O cuidado, a dedicação e a busca constante de melhores condições para a preservação do acervo arqueológico mantido sob a guarda do Museu Goeldi, foram nacionalmente reconhecidos em 1998, quando a instituição recebeu do IPHAN o Prêmio "Rodrigo Melo Franco de Andrade", na categoria "Patrimônio Natural e Arqueológico", concedido pelo seu destaque na preservação, apoio e divulgação do patrimônio nacional.

Em 2005, o Projeto de Educação Patrimonial realizado em Canaã dos Carajás -no âmbito de um projeto de contrato - recebeu da Sociedade de Arqueologia Brasileira o Prêmio "Loureiro Fernandes", devotado a ações educativas com a finalidade de estimular estratégias pedagógicas que difundam amplamente os conhecimentos sobre a Arqueologia Brasileira. Esse mesmo projeto foi classificado entre os 30 finalistas do Prêmio Cultura Viva, do Ministério da Cultura.

As premiações recebidas pelo projeto desenvolvido em Canaã dos Carajás demarcam, pelo menos na Amazônia, um momento significativo na existência e realização de programas de pesquisa arqueológica integrados a programas de educação patrimonial. $\bigcirc$ mérito desses prêmios provavelmente se deve aos seguintes aspectos, que caracterizaram o projeto: sua natureza inter e transdisciplinar, que permitiu a integração de profissionais de diversas áreas, como arqueologia, educação, arte e turismo; seu caráter não-formal, que possibilitou a inclusão de moradores locais de diversas faixas etárias, diversos níveis de escolaridade ou sem escolaridade nenhuma, diversas profissões e também pessoas sem uma profissão definida.

Os princípios teóricos e metodológicos que nortearam o projeto foram importantes também, pois definiram: a) seu caráter teórico-prático, ou seja, teoria e prática foram tratadas de forma inseparável, evitando-se verbalismos sem ação e ativismos sem reflexão; b) os processos educativos foram exercidos como processos culturais e não apenas como transmissores de cultura, propiciando o protagonismo social. 
Ainda no ano de 2005, o livro "Arte rupestre na Amazônia" foi premiado pela Academia Paulistana de História, além de ficar classificado entre os dez finalistas do Prêmio Jabuti - o mais tradicional e importante prêmio literário brasileiro - em duas categorias: melhor livro de ciências humanas e melhor projeto gráfico.

\section{AÇÕES DIVERSAS}

Em 1998, uma parceria entre o Museu Goeldi e o Serviço de Apoio às Micro e Pequenas Empresas do Estado do Pará (Sebrae) no âmbito do Projeto Pará Artesanal resultou em um conjunto de atividades voltadas para o incentivo da produção e renovação do artesanato com inspiração arqueológica. Nesse sentido, foi ministrado um curso sobre as culturas pré-históricas da Amazônia a um grupo de ceramistas de Icoaraci, distrito de Belém conhecido pela produção de cerâmica com inspiração arqueológica, particularmente a marajoara, a tapajônica e a maracá. A arte rupestre da Amazônia, até então pouco conhecida, foi também apresentada aos artesãos.

Dessa parceria resultou uma exposição com 50 réplicas de cerâmica arqueológica e peças cerâmicas contemporâneas utilizando grafismos arqueológicos, bem como a publicação do livro "Arte da Terra - resgate da cultura material e iconográfica do Pará". Esse livro, elaborado com linguagem acessível e fartamente ilustrado, apresenta informações sobre a arte rupestre da Amazônia, as culturas Marajoara, Tapajônica, Maracá e também sobre artefatos indígenas contemporâneos.

O livro esgotou rapidamente, transformando-se em uma importante fonte de inspiração para o artesanato local. A arte rupestre, até então desconhecida e ausente do artesanato regional, transformou-se em um elemento presente em todo tipo de produto, desde a simples camiseta de algodão, passando por sacolas, quadros, bonés, bijuterias e até jóias em ouro e prata. $O$ alcance que o livro teve (e ainda tem) entre o público leigo tem refletido positivamente para a divulgação da pré-história da Amazônia e para a necessidade de preservar o patrimônio arqueológico.
A turistificação de sítios arqueológicos é um tema recente e ainda pouco debatido no país, que o Museu Goeldi abraçou como um novo desafio. Nesse sentido, a instituição promoveu, em 2005, o Fórum de Debates sobre Arqueologia e Turismo na Amazônia. Esse evento, um dos pioneiros no país, teve como objetivo refletir sobre a prática do turismo em sítios arqueológicos, analisando problemas e oportunidades e propondo medidas para que o turismo possa ocorrer de forma organizada e instrutiva, sem causar danos ao patrimônio arqueológico e trazendo benefícios para as comunidades onde os sítios estão localizados. A segunda edição desse Fórum aconteceu em setembro de 2008.

Esse novo desafio se traduz não apenas na realização de eventos para debater o tema, mas também no incentivo à pesquisa relacionada ao turismo em sítios arqueológicos. Nesse sentido, destacam-se os trabalhos de Pereira e Figueiredo (2005), Figueiredo e Pereira (2007), Guedes (2007), Nogueira (2007), Baccino (2007), Moreira (2007), Barroso (2007) e Farias (2006).

Atendendo a uma necessidade há muito sentida pelos arqueólogos que atuam na região, o Museu Goeldi, em parceria com o IPHAN e a Secretaria de Cultura do Estado do Pará, realizou em setembro de 2008 o Encontro Internacional de Arqueologia Amazônica. Esse evento reuniu os profissionais que atuam na região em um intenso intercâmbio de informações, um momento para a reflexão e avaliação das pesquisas arqueológicas realizadas na Amazônia nos últimos 20 anos.

Ações como as descritas nas páginas anteriores mostram o compromisso do Museu Goeldi com a pesquisa, a proteção, a difusão e a educação relacionadas ao patrimônio arqueológico do país. Consciente do seu papel na Amazônia, o Museu Goeldi não mede esforços para colaborar com outras instituições da região que têm material arqueológico sob a sua guarda. Partidário da permanência do patrimônio arqueológico na sua região de origem, o Museu Goeldi, por meio da Área de Arqueologia, tem colaborado na organização do acervo arqueológico de 
diversas instituições localizadas no Pará, como a Fundação Casa da Cultura de Marabá (Pereira, 2002a), o Museu Integrado de Óbidos (Lopes, 1999a) e o Centro Cultural João Fona, em Santarém (Guapindaia, 1998). Além dessas instituições, o Museu Goeldi tem colaborado com o Museu do Marajó, em Cachoeira do Arari, desde 1993.

Acontecimentos recentes ocorridos em torno de uma coleção arqueológica formada majoritariamente por peças provenientes do estado do Pará precisam ser mencionados, na medida em que estão na contramão das recomendações nacionais e internacionais de repatriação do patrimônio arqueológico. Trata-se de uma coleção formada por meios não oficiais pelo Sr. Edmar Cid Ferreira, proprietário do Banco Santos, que estava sob a guarda oficial do Instituto Cultural Banco Santos. Em dezembro de 2004, foi decretada a intervenção no Banco Santos. Tão logo tomou ciência desse fato, o Museu Goeldi, preocupado com a situação de vulnerabilidade institucional desse patrimônio e com o seu destino, se pronunciou formalmente ao Ministério da Cultura e ao IPHAN, colocando-se à disposição para assumir a guarda da coleção.

As questões relacionadas com o Banco Santos estavam nas mãos de um juiz de São Paulo, ligado à Vara de crimes contra o sistema financeiro e que, indiferente às recomendações nacionais e internacionais de repatriação do patrimônio arqueológico e à solicitação de guarda feita pelo Museu Goeldi, decidiu dar a guarda da referida coleção ao Museu de Arqueologia e Etnologia da Universidade de São Paulo. Ressalta-se que a determinação da guarda de bens arqueológicos é de competência constitucional do IPHAN, que, nesse caso, parece não ter sido ouvido. Hoje, o Museu Goeldi, com o apoio do IPHAN, luta na Justiça para que a decisão do juiz seja revertida de forma a possibilitar que a Amazônia possa ter de volta um patrimônio que the foi retirado de forma ilegal.

Em 1966, ao avaliar os primeiros cem anos da pesquisa arqueológica na Amazônia, Clifford Evans (1967) identificou alguns problemas que persistem até os dias de hoje, como a carência de pesquisa científica na região e a destruição de sítios arqueológicos em razão do desenvolvimento urbano e da expansão da agricultura. Se considerarmos as dimensões geográficas da região, constataremos que muito já foi feito, mas que ainda há muito a fazer. Existem na Amazônia grandes áreas sobre as quais nada se conhece, enquanto outras concentram um número importante de pesquisas. Centenas de sítios já foram pesquisados, mas muitos ainda estão por ser descobertos e outros tantos estão irremediavelmente destruídos sem que qualquer estudo tenha sido feito. Há, portanto, muito a se fazer.

Desde que Ferreira Penna criou a Sociedade Filomática - origem do Museu Goeldi - os avanços foram muitos. A trajetória dessa instituição é marcada por importantes contribuições para a pesquisa arqueológica e para o conhecimento da ocupação humana na região. Desde a descoberta dos poços artificiais de Cunani, feita no século XIX por Emílio Goeldi, passando pela contribuição dada por Mário Simões para a arqueologia na Amazônia durante mais de duas décadas, até os dias de hoje, quando as pesquisas se diversificaram abrangendo da mais remota ocupação humana até o período histórico.

Em 1966, durante o Simpósio da Biota Amazônica, Clifford Evans (1967) expressou a sua expectativa com relação ao futuro da pesquisa arqueológica na Amazônia da seguinte maneira:

\begin{abstract}
É minha esperança sincera que quando o Museu Paraense "Emilio Goeldi" comemore os 200 anos de sua fundação - em 2066 - o panorama arqueológico seja totalmente diferente do que é hoje. Entretanto, eu estou orgulhoso de relatar que durante estes primeiros 100 anos, o Museu Paraense "Emilio Goeldi" foi um líder em patrocinar e dirigir a pesquisa arqueológica na Amazônia, compartilhando às vezes as honras com uma outra instituição brasileira, o Museu Nacional.
\end{abstract}

Não será preciso esperar tanto tempo para constatar que o panorama arqueológico da Amazônia mudou bastante desde a década de 1960. Hoje, a 
realidade da região é outra, mas alguns dos problemas mencionados por Evans naquela época ainda persistem. O que se mantêm desde então é o destaque do Museu Goeldi na realização de pesquisas arqueológicas na região e nas ações para a preservação do legado material deixado por nossos antepassados.

\section{REFERÊNCIAS}

ALVES, José Jerônimo de Alencar. Métodos Geofísicos Aplicados à Arqueologia no Estado do Pará, 1979. Dissertação (Mestrado em Ciências Geofísicas e Geológicas) - Universidade Federal do Pará, Belém, 1979

ALVES, José Jerônimo de Alencar; LOURENÇO, José Seixas. Métodos Geofísicos Aplicados à Arqueologia no Estado do Pará. Boletim do Museu Paraense Emílio Goeldi, série Geologia, v. 26, p. 1-52, 1981.

ANDERSON, Scott Douglas; MARQUES, Fernando Luiz Tavares; NOGUEIRA, Manoel Fernandes Martins. The Use of Traditional Technology for Rural Development: The Case of Tidal Energy near the Mouth of the Amazon. Advances in Economic Botany, v. 13, 1999.

ANDERSON, Scott Douglas; MESQUITA, André Luiz Amarante; ALENCAR JR., Julio Augusto; MARQUES, Fernando Luiz Tavares. O Uso do Rotor Darrieus para Gerar Eletricidade no Estuário do Amazonas. In: ENCONTRO LATINO AMERICANO DE FLUIDOMECÂNICA, 4., 1997, Itajubá. Anais... Itajubá: Escola Federal de Engenharia de Itajubá, 1997.

ANDERSON, Scott Douglas; MESQUITA, André Luiz Amarante; ALENCAR JR., Julio Augusto; NOGUEIRA, Manoel Fernandes Martins; MARQUES, Fernando Luiz Tavares. A maré como fonte energética na costa norte brasileira: tecnologias de aproveitamento e regiões com potencial para implantação. In: ENCONTRO PARA O DESENVOLVIMENTO DE ENERGIAS RENOVÁVEIS, 3., 1996, São Paulo. Anais... São Paulo: IDER, 1996.

ANDERSON, Scott Douglas; MARQUES, Fernando Luiz Tavares; NOGUEIRA, Manoel Fernandes Martins. Tide-generated energy at the estuary of the Amazon: the use of traditional technology to support modern development. Renewable Energy, n. 3, 1993.

ANDERSON, Scott Douglas; MARQUES, Fernando Luiz Tavares. Engenhos movidos à maré no estuário do amazonas: vestígios encontrados no município de Igarapé-miri, Pará. Boletim do Museu Paraense Emílio Goeldi, série Antropologia, v. 8, n. 2, 1992.

ANDERSON, Scoth Douglas; NOGUEIRA, Manoel Fernandes Martins; MARQUES, Fernando Luiz Tavares. A energia da maré: resgate de uma tecnologia tradicional do estuário do amazonas. In: ENCONTRO DE CIÊNNCIAS SOCIAIS E O MAR NO BRASIL, 4., 1992a, São Paulo. Anais... São Paulo: Universidade de São Paulo, 1992.
ARAGÃO, Rigler da Costa. Metodologia geofísica aplicada a estudos arqueológicos nos sítios Bittencourt, Jambuaçu e Jaburu, Estado do Pará, 2006. Dissertação (Mestrado em Geofísica) Universidade Federal do Pará, Belém, 2006.

ARAGÃO, Rigler da Costa; LUIZ, José Gouvêa; LOPES, Paulo Roberto do Canto. Metodologia geofísica aplicada a salvamento arqueológico de área adjacente a mineroduto no Nordeste do Pará. In: CONGRESSO INTERNACIONAL DA SOCIEDADE BRASILEIRA DE GEOFÍSICA, 9., 2005, Salvador. Anais... Salvador: Sociedade Brasileira de Geofísica, 2005.

ARAÚJO COSTA, Fernanda; NEVES, Walter Alves; CALDARELLI, Solange Bezerra. Rescue Archaeology in Brazilian Amazon: retrospect and perspectives. In: Archaeology and Society. Stockholm: ICAHM Report, 1988. n. 1, p. 277-286.

ATIKUM, Nilza Firmina de Lucena. Povo indígena da aldeia Kanaí. Belém: Museu Paraense Emílio Goeldi, 2005.

BACCINO, Marcelo Pamplona. Práticas de turismo no Parque da Serra dos Martírios/Andorinhas: estudos de potencialidades, 2007. Trabalho de Conclusão de Curso (Graduação em Bacharelado em Turismo) - Universidade Federal do Pará, Belém, 2007.

BARBOSA, Carlos Augusto Palheta. As urnas funerárias da região de Maracá (AP): Uma visão cosmológica do espaço vivido, 2001. Trabalho de Conclusão de Curso (Bacharelado em Geografia) - Universidade Federal do Pará, Belém, 2001.

BARRADAS, João Augusto; SCHAAN, Denise Pahl; LUIZ, José Gouvêa. Magnetic and GPR Survey to Identify Archaeological Features on Cacoal Site, Anajás River, Marajó Island, Pará, Brazil. In: CONGRESSO INTERNACIONAL DA SOCIEDADE BRASILEIRA DE GEOFÍSICA, 6., 1999, Rio de Janeiro. Anais... Rio de Janeiro: Sociedade Brasileira de Geofísica, 1999. 1 CD-ROM.

BARRETO, Mauro Viana. A história da pesquisa arqueológica no Museu Paraense Emílio Goeldi. Boletim do Museu Paraense Emílio Goeldi, série Antropologia, v. 8, n. 2, p. 203-294, 1992.

BARROSO, Mary Rodrigues. Turismo e Arqueologia: Uma Proposta de Valorização Histórico-Cultural do Sítio Jaguarari, no Município de Moju, Pará, 2007. Trabalho de Conclusão de Curso (Bacharelado em Turismo) - Universidade Federal do Pará, Belém, 2007.

BEVAN, B.W.; ROOSEVELT, A. C. Geophysical Exploration of Guajará, a prehistoric earth mound in Brazil. Geoarchaelogy, v. 18, n. 3, p. 287-331, 2003.

BUENO, Lucas, MACHADO; Juliana Sales S. Relatório Final de Levantamento Arqueológico da área de implantação do sistema de Transmissão 230 kV ji-Paraná/ Pimenta Bueno/ Vilhena - RO. Relatório técnico. Belém: Museu Paraense Emílio Goeldi, 2005.

CALDARELLI, Solange Bezerra; SANTOS, Maria do Carmo Mattos M. dos. Arqueologia de Contrato no Brasil. Revista da USP, v. 44, n. 1, p. 52-73, 2000.

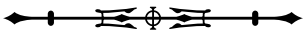


COIROLO, Alicia Durán. Salvamento arqueológico no sítio Ilha de Terra, região de Caxiuanã, Melgaço (PA). Relatório de campo. Belém: Museu Paraense Emílio Goeldi, 2004.

COIROLO, Alicia Durán. Salvamento arqueológico no Município de Calçoene. Relatório técnico. Belém: Museu Paraense Emílio Goeldi, 1996.

COIROLO, Alicia Durán; D'AQUINO, Gilma Isabel do Rego. Salvamento Arqueológico no Sítio Ilha de Terra, Região de Caxiuanã, Melgaço, Pará. In: CONGRESSO DA SOCIEDADE DE ARQUEOLOGIA BRASILEIRA, 13., 2005, Campo Grande. Anais... Campo Grande: Sociedade de Arqueologia Brasileira, 2005.

CORRÊA, Conceição Gentil. Horticultores pré-históricos do Pará, Brasil. Revista de Arqueologia, v. 4, n. 2, p. 139-252, 1987.

CRUZ, Roberto Borges da. Caçadores-coletores da Amazônia Pré-histórica: o caso Carajás, 2002. Trabalho de Conclusão de Curso (Graduação em História) - Universidade Federal do Pará, Belém, 2002.

CRUZ, Deusarina; LIMA, Janice; SOEIRO, Milton; OLIVEIRA, Simone. Uma visita ao sítio arqueológico. Belém: Museu Paraense Emílio Goeldi, 2004.

CUNHA, Ana Paula Macedo; COSTA, Dayseane Ferraz da; MARQUES, Fernando Luiz Tavares. Um Passeio Cultural: Sítios Arqueológicos na Alça Viária. Belém: MCT-MPEG/SETRANS-PA/ FADESP, 2004.

D'AQUINO, Gilma Isabel do Rego. Os Cachimbos Tubulares Falomorfos Cerâmicos de Alenquer/PA. Revista CLIO, Série Arqueológica, n. 16, v. 1, p. 193-201, 2003.

D'AQUINO, Gilma Isabel do Rego. O fumo e os cachimbos cerâmicos na pré-história da Amazônia Brasileira - Os "sambaquis" de Alenquer e os Tapajó de Santarém, 2001. Dissertação (Mestrado em História) - Universidade Federal de Pernambuco, Recife, 2001.

EVANS, Clifford. Amazon Archeology - a centennial appraisal. Atas do Simpósio sobre a Biota Amazônica, Antropologia, v. 2, p. 1-12, 1967.

FARIAS, Ana Priscila de Souza. Turismo Arqueológico: oportunidades e ameaças no sítio arqueológico da Vila de Joanes (Salvaterra, Pará), 2006. Trabalho de Conclusão de Curso (Bacharelado em Turismo) - Universidade Federal do Pará, Belém, 2006.

FIGUEIREDO, Silvio José de Lima. Educação Patrimonial em Abaetetuba e Moju/PA. Documentário. Direção de Sílvio Figueiredo. Belém: MPEG/FIDESA/CVRD, 2007. 1 DVD (17 min), son., color.

FIGUEIREDO, Silvio José de Lima. Arqueologia. Vídeo. Direção de Sílvio Figueiredo. Belém: MPEG/FIDESA/CVRD, 2006. 1 DVD (13 min), son., color
FIGUEIREDO, Silvio José de Lima. Arqueologia e Educação em Canaã dos Carajás. Documentário. Direção de Sílvio Figueiredo. Belém: MPEG/FIDESA/CVRD, 2005. 1 videocassete/1 DVD (30 min), VHS, son., color.

FIGUEIREDO, Silvio José Lima; PEREIRA, Edithe. Turismo e Arqueologia na Amazônia Brasil: aspectos de preservação e planejamento. In: SEMINÁRIO DA ASSOCIAÇÃO NACIONAL DE PESQUISA E PÓS-GRADUAÇÃO EM TURISMO, 4. 2007, São Paulo. Anais... São Paulo: Anptur/Universidade Anhembi-Morumbi, 2007. v. 1, p. 235-250

FONSECA JR., João Aires Ataíde. História dos Ídolos de Pedra Amazônicos, 2004. Trabalho de Conclusão de Curso (Licenciatura em História) - Universidade Federal do Pará, Belém, 2004

FUNARI, Pedro Paulo. Arqueologia. São Paulo: Contexto, 2003.

GASPAR, Maria Dulce; IMAZIO, Maura. Os pescadores-coletorescaçadores do litoral norte brasileiro. In: TENÓRIO, Maria Cristina (Org.). Pré-história da Terra Brasilis. Rio de Janeiro: Editora UFRJ, 1999. p. 247-256.

GUAPINDAIA, Vera Lúcia Calandrini. Além da margem do rio: as ocupações Konduri e Pocó na região de Porto Trombetas, PA, 2008. Tese (Doutorado em Arqueologia) - Universidade de São Paulo, São Paulo, 2008a.

GUAPINDAIA, Vera Lúcia Calandrini. Prehistoric Funeral Practices in the Brasilian Amazon: The Maracá Urns. In SILVERMAN, Helaine; ISBELL, William H. (Orgs.). Handbook of South American Archaeology. New York: Springer, 2008b. v. 1 , p. $1005-1026$

GUAPINDAIA, Vera Lúcia Calandrini. Encountering the Ancestors: The Maracá Urns. In: McEWAN, Collin; BARRETO, Cristiana; NEVES, Eduardo (Orgs.). Unknown Amazon. Londres: The British Museum Press, 2001. p. 156-173.

GUAPINDAIA, Vera Lúcia Calandrini. Práticas Funerárias na região do Igarapé do Lago, rio Maracá, Amapá: considerações preliminares. Revista CLIO, série Arqueológica, n. 14, p. 55-66, 2000.

GUAPINDAIA, Vera Lúcia Calandrini. A Cerâmica Maracá: História e Iconografia. In: Arte da Terra: resgate da cultura material e iconográfica do Pará. Belém: Museu Paraense Emílio Goeldi/SEBRAE, 1999. p. 44-53.

GUAPINDAIA, Vera Lúcia Calandrini. Relatório das atividades realizadas no Centro Cultural João Fona em Santarém, Pará. Belém: Museu Paraense Emílio Goeldi, 1998.

GUAPINDAIA, Vera Lúcia Calandrini. Fontes Históricas e Arqueológicas sobre os Tapajó de Santarém - A coleção Frederico Barata do Museu Paraense Emílio Goeldi, 1993. Dissertação (Mestrado em História) - Universidade Federal de Pernambuco, Recife, 1993. 
GUAPINDAIA, Vera Lúcia Calandrini; SCHAAN, Denise Pahl; LOPES, Paulo Roberto do Canto. Levantamento Arqueológico na Linha de Transmissão Tucuruí-Vila do Conde (PA). Relatório técnico. Belém: Museu Paraense Emílio Goeldi, 1998.

GUAPINDAIA, Vera Lúcia Calandrini; MACHADO, Ana Lúcia da Costa. O Potencial Arqueológico da Região do Rio Maracá/lgarapé do Lago (AP). Boletim do Museu Paraense Emílio Goeldi, série Antropologia v. 13 n. 1, p. 67-102, 1997.

GUAPINDAIA, Vera Lúcia Calandrini; MACHADO, Ana Lúcia da Costa; SILVEIRA, Isolda Maciel; QUARESMA, Helena Dóris. As Populações Pré-históricas e Atuais em Caxiuanã (PA). In: LISBOA, Pedro L. B. (Org.) Caxiuanã. Belém: Museu Paraense Emilio Goeldi, 1996. p. 53-81.

GUEDES, Josiel Rodrigues. Estudo da Capacidade de Carga Turística dos Sítios Arqueológicos de Arte Rupestre da Serra das Andorinhas - Pará, 2007. Trabalho de Conclusão de Curso (Bacharelado em Turismo) - Universidade Federal do Pará, Belém, 2007.

HECKENBERGER, Michael J.,; RUSSELL, J. Christian; FAUSTO Carlos; TONEY Joshua R.; SCHMIDT, Morgan J.; PEREIRA, Edithe; FRANCHETTO, Bruna; KUIKURO, Afukaka. The archaeology of pre-Columbian polities in the Amazon River basin forces a reconsideration. Science, v. 321, p. 1214-1217, 2008.

HECKENBERGER, Michael J. The Ecology of Power: Culture, Place, and Personhood in the Southern Amazon, A.D. 1000-2000. New York/London: Routledge, 2005.

LEAL, Vânia. Grafismo da cerâmica arqueológica de Canaã dos Carajás: proposta de uso em produtos contemporâneos. Belém: Museu Paraense Emílio Goeldi, 2005.

LIMA, Janice. Caderno de Educação para o Patrimônio Arqueológico n. 2. Belém: MPEG, $2006 a$.

LIMA, Janice. Caderno de Educação para o Patrimônio Arqueológico n. 3. Belém: MPEG, 2006b.

LIMA, Janice. Acendendo memórias entre territórios. In: MOKARZEL, Marisa. (Org.). Estudos de artes visuais e suas interfaces. Belém: Unama, 2006c. p. 31-56 (Linguagens: Estudos interdisciplinares e multiculturais, v. 5).

LIMA, Janice. Relações interculturais: apresentação do Projeto de educação para o patrimônio arqueológico em comunidades ribeirinhas dos Municípios de Abaetetuba e Moju. Belém: MPEG/ CVRD/FIDESA, 2005a.

LIMA, Janice. Caderno de Educação para o Patrimônio Arqueológico n. 1. Belém: MPEG/CVRD/FIDESA, 2005b.

LIMA, Janice. Educação Patrimonial e Arqueologia de Contrato - a experiência de Canaã dos Carajás. In: In: CONGRESSO DA SOCIEDADE DE ARQUEOLOGIA BRASILEIRA, 13., 2005, Campo Grande. Anais... Campo Grande: Sociedade de Arqueologia Brasileira, 2005c. 1 CD-ROM.
LIMA, Janice. Educação Patrimonial na Área do Projeto Serra do Sossego Canaã dos Carajás (PA). Belém: MPEG/CVRD-MSS/ FIDESA, 2003.

LIMA, Janice; PEREIRA, Edithe. Arqueologia e educação no interior da Amazônia - o exemplo de Canaã dos Carajás (PA). In: SEMANA DOS MUSEUS DA UNIVERSIDADE DE SÃO PAULO - AÇÕES AFIRMATIVAS EM MUSEUS: EDUCAR E PRESERVAR, 5., 2007, São Paulo. Resumos... São Paulo: Universidade de São Paulo, 2007. 1 CD-ROM.

LIMA, Janice; MACHADO, Vânia Leal. Arqueologia e Arte: processos de ensino-aprendizagem do Projeto de Educação Patrimonial na Área do Sossego em Canaã dos Carajás (PA). In: MARTINS, A. F.; COSTA, L. E.; MONTEIRO, R. H. (Orgs.). Cultura visual e desafios da pesquisa em artes. Goiânia: ANPAP, 2005. 2 v, p. 387-397.

LOPES, Paulo Roberto do Canto. Levantamento do acervo Arqueológico, Etnográfico e Documental do Museu Integrado de Óbidos - Pará. Relatório. Belém: Museu Paraense Emílio Goeldi, 1999a.

LOPES, Paulo Roberto do Canto. A Colonização Portuguesa da Ilha de Marajó: Espaço e Contexto Arqueológico-Histórico na Missão Religiosa de Joanes, 1999. Dissertação (Mestrado em História) - Pontifícia Universidade Católica do Rio Grande do Sul, Porto Alegre, 1999b.

LOPES, Paulo Roberto do Canto; NASCIMENTO, Ivete; SENNA, Cristina do Socorro; RUIVO, Maria de Lourdes; LUIZ, José Gouvêa. Linking Archaeology with local Communities in Amazonia: An Ethnoarchaeological study in the Bauxite Paragominas Project, Pará, Brazil. In: SOCIETY FOR AMERICAN ARCHAEOLOGY 71ST ANNUAL MEETING, 71., 2006, San Juan . Anais... San Juan: Society for American Archaeology, 2006.

LUIZ, José Gouvêa; ARAGÃO, Rigler da Costa; LOPES, Paulo Roberto do Canto. Métodos magnético e cintilométrico aplicados ao salvamento arqueológico do sítio Jaburu do rio Paru. In: INTERNATIONAL CONGRESS OF THE BRAZILIAN GEOPHYSICAL SOCIETY, 10., 2007, Rio de Janeiro. Anais... Rio de Janeiro: Sociedade Brasileira de Geofísica, 2007a.

LUIZ, José Gouvêa; ARAGÃO, Rigler da Costa; LOPES, Paulo Roberto do Canto. Métodos magnético e cintilométrico aplicados ao salvamento arqueológico. In: INTERNATIONAL CONGRESS OF THE BRAZILIAN GEOPHYSICAL SOCIETY, 10., 2007, Rio de Janeiro. Anais... Rio de Janeiro: Sociedade Brasileira de Geofísica, 2007b.

LUIZ, José Gouvêa; PEREIRA, Edithe. Prospecção arqueológica por métodos geofísicos no sudeste do Pará: o caso do Sítio Domingos. Canaã dos Carajás. In: INTERNATIONAL CONGRESS OF THE BRAZILIAN GEOPHYSICAL SOCIETY, 9., 2005, Salvador. Anais.. Salvador: Sociedade Brasileira de Geofísica, 2005.

MACHADO, Ana Lúcia da Costa. Relatório do salvamento arqueológico no sítio AP-MA-5: Campus Universitário, Macapá (AP). Belém: Museu Paraense Emílio Goeldi, 1997.

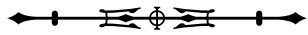


MAGALHÃES, Marcos Pereira. O Homem das cavernas de Carajás. In: TEIXEIRA, João Batista Guimarães; BEISIEGEL, Vanderlei de Rui (Orgs.). Carajás: geologia e ocupação humana. Belém: Museu Paraense Emílio Goeldi, 2006a. p. 91-126.

MAGALHÃES, Marcos Pereira. Arqueologia na Fortaleza de São José de Macapá. Boletim do Museu Paraense Emílio Goeldi. Ciências Humanas, v. 1, n. 3, p. 33-59, 2006 b.

MAGALHÃES, Marcos Pereira. A Physis da Origem: o sentido da história na Amazônia. Belém: Museu Paraense Emílio Goeldi, 2005a.

MAGALHÃES, Marcos Pereira. Levantamento Arqueológico no Alto Rio Madeira. Belém: Museu Paraense Emílio Goeldi, 2005b.

MAGALHÃES, Marcos Pereira. Caçadores-Coletores na Amazônia. In: CONGRESSO DA SOCIEDADE DE ARQUEOLOGIA BRASILEIRA - ARQUEOLOGIA, PATRIMÔNIO E TURISMO, 13., 2005, Campo Grande. Anais... Campo Grande: Sociedade de Arqueologia Brasileira, 2005c. 1 CD-ROM.

MAGALHÃES, Marcos Pereira. Levantamento arqueológico ao longo das BR's 230 (PA): Transamazônica e 422 (PA): Novo Repartimento-Tucuruí. Relatório de pesquisa. Belém: Museu Paraense Emílio Goeldi, 2003.

MAGALHÃES, Marcos Pereira. Relatório da Prospecção Arqueológica no Traçado da Alça Rodoviária. Relatório técnico. Belém: Museu Paraense Emílio Goeldi, 2002a.

MAGALHÃES, Marcos Pereira. Caçadores-Coletores préagricultores da Gruta do Pequiá. In: CONGRESSO DA SOCIEDADE DEARQUEOLOGIA BRASILEIRA, 11., 2002, Rio de Janeiro. Anais... Rio de Janeiro: Sociedade de Arqueologia Brasileira, 2002b.

MAGALHÃES, Marcos Pereira. Nota sobre três pontas-de-projétil provenientes da bacia do rio Xingu (Pará, Brasil). Boletim do Museu Paraense Emílio Goeldi, série Antropologia, v. 18, n. 1, p. 89-105, 2002c.

MAGALHÃES, Marcos Pereira. Relatório de prospecção arqueológica do projeto de estudos arqueológicos na linha de Transmissão Tramo-Oeste, trecho Altamira-Rurópolis. Relatório técnico. Belém: Museu Paraense Emílio Goeldi, 2001.

MAGALHÃES, Marcos Pereira. Prospecções Arqueológicas no rio Capim. Relatório técnico. Belém: Museu Paraense Emílio Goeldi, 2000.

MAGALHÃES, Marcos Pereira. As Origens das Sociedades Amazônicas. In: REUNIÃO CIENTÍFICA DA SOCIEDADE DE ARQUEOLOGIA BRASILEIRA, 10., 1999, Recife. Anais... Recife: Universidade de São Paulo, 1999.

MAGALHÃES, Marcos Pereira. Os novos achados arqueológicos em Carajás.. In: CONGRESSO INTERNACIONALDEARQUEOLOGIA BRASILEIRA, 9., 1997, Rio de Janeiro. Anais... Rio de Janeiro: Sociedade de Arqueologia Brasileira, 1997.
MAGALHÃES, Marcos Pereira. Arqueologia de Carajás. Rio de Janeiro: CVRD, 1994a.

MAGALHÃES, Marcos Pereira. The pre-historic presence of man in Amazonia. Rio de Janeiro: CVRD, 1994b.

MAGALHÃES, Marcos Pereira. A Gruta do Gavião. American Antiquity, v. 59, n. 01, p. 98-99, 1993.

MAGALHÃES, Marcos Pereira. Oito Mil Anos Antes do Presente, 1990. Dissertação (Mestrado em História Social) - Universidade Federal do Rio de Janeiro, Rio de Janeiro, 1990.

MARQUES, Fernando Luiz Tavares. Investigação arqueológica na Feliz Luzitânia. In: Secretaria Executiva de Cultura do Estado (Org.). Feliz Luzitânia/Forte do Presépio - Casa das Onze Janelas - Casario da Rua Padre Champanhat. Belém: SECULT-PA, 2006. v. 4, p. 147-190.

MARQUES, Fernando Luiz Tavares. Levantamento Arqueológico Histórico na Área de Influência da Construção da Hidrelétrica Jirau, Alto Rio Madeira, Rondônia. Relatório técnico (final). Belém: Museu Paraense Emílio Goeldi, 2005a.

MARQUES, Fernando Luiz Tavares. Prospecção Arqueológica no Palácio Episcopal de Belém. In: Secretaria Executiva de Cultura do Estado (Org.). Feliz Lusitânia/ Museu de Arte Sacra - Série Restauro. Belém: SECULT, 2005b. v. 3, p. 1-308.

MARQUES, Fernando Luiz Tavares. Modelo da Agroindústria Canavieira Colonial no Estuário Amazônico: Estudo Arqueológico de Engenhos dos Séculos XVIII e XIX, 2004. Tese (Doutorado em História) - Pontifícia Universidade Católica do Rio Grande do Sul, Porto Alegre, 2004

MARQUES, Fernando Luiz Tavares. Organização Espacial e Cultura Material no Engenho Murutucu: uma abordagem arqueológica. In: Landi e o Século XVIII na Amazônia, 2003a.

MARQUES, Fernando Luiz Tavares. Programa de salvamento e monitoramento de sítios arqueológicos no traçado da Alça Rodoviária - Belém/PA. Relatório técnico. Belém: Museu Paraense Emílio Goeldi, 2003b.

MARQUES, Fernando Luiz Tavares. Programa de salvamento e monitoramento de sítios arqueológicos no traçado da Alça Rodoviária - Belém/PA. Relatório técnico. Belém: Museu Paraense Emílio Goeldi, 2002.

MARQUES, Fernando Luiz Tavares. Engenhos de Maré em Barcarena, Pará: Arqueologia de seus sistemas Motrizes, 1993. Dissertação (Mestrado em História) - Pontifícia Universidade Católica do Rio Grande do Sul, Porto Alegre, 1993.

MARQUES, Fernando Luiz Tavares; SCHAAN, Denise Pahl. Projeto Preservação, conservação, pesquisa e educação patrimonial no sítio histórico de Joanes. Relatório final. Belém: Museu Paraense Emílio Goeldi/Instituto do Patrimônio Histórico e Artístico Nacional, 2006. 
MARTINS, Cristiane Maria Pires. O sítio arqueológico Bitoca 2: contribuições provenientes da análise do material cerâmico, 2007a. Monografia (Especialização em FIPAM XXI) - Núcleo de Altos Estudos Amazônicos/Universidade Federal do Pará, Belém, 2007a.

MARTINS, Vitor Nazareno da Mata. Estudo histórico, organização, análise e descrição da coleção Protásio Frikel. In: II Seminário do Programa de Capacitação Institucional (PCI). Belém: Museu Paraense Emílio Goeldi, 2007b.

MARTINS, Vitor Nazareno da Mata. A Cerâmica de Caxiuanã Mais um vestígio deixado pelo homem Pré-histórico Amazônico, 2005. Trabalho de Conclusão de Curso (Licenciatura em História) - Universidade Federal do Pará, Belém, 2005.

MOREIRA, Gisele Lopes. Turismo e Arqueologia: Uma Proposta de Valorização Histórico-Cultural do Sítio Jaguarari, no Município de Moju, Pará, 2007. Trabalho de Conclusão de Curso (Bacharelado em Turismo) - Universidade Federal do Pará, Belém, 2007.

MUSEU PARAENSE EMÍLIO GOELDI. Relatório Anual da Coordenação de Ciências Humanas do Museu Paraense Emílio Goeldi. Belém, 2002.

NASCIMENTO, Hannah Fernandes. Por uma Antropologia da Arqueologia: as possibilidades de percepções do contato entre arqueólogo e moradores da Vila de Guajaraúna, Moju/PA, 2006. Trabalho de Conclusão de Curso (Graduação em Ciências Sociais) - Universidade Federal do Pará, Belém, 2006.

NOGUEIRA, Marcela Andrade. Turismo e Arqueologia na Amazônia: Planejamento e Visitação de Sítios Arqueológicos na Região da Serra dos Martírios/Andorinhas, 2007. Trabalho de Conclusão de Curso (Bacharelado em Turismo) - Universidade Federal do Pará, Belém, 2007.

OLIVEIRA, Rita Denise de; RUIVO, Maria de Lourdes; LOPES Paulo Roberto do Canto; RODRIGUES, Tarcísio Ewerton. Análise Preliminar da Morfologia e da Micromorfologia de alguns solos antrópicos dos municípios de Barcarena, Abaetetuba e Moju no nordeste do Pará. In: CONGRESSO BRASILEIRO DE CIÊNCIAS DO SOLO, 30., 2005, Recife. Anais... Recife: Universidade Federal do Rio Grande do Sul, 2005.

OLIVEIRA, Aldeídes G.; MACHADO, Chritiane Lopes; MAGALHÃES, Cíntia Jales; ÁLVARO, Maria Angel Gemaque; BARRETO, Mauro Viana; MELLO, Paulo Jobim C.; MURRIETA, Rui Sérgio Sereni. Arqueólogos e populações ribeirinhas. Cadernos do Centro de Filosofia e Ciências Humanas, n. 1, p. 37-60, 1988.

PENNA, Domingos Soares Ferreira. Obras completas de Domingos Soares Ferreira Penna. Belém: Conselho Estadual de Cultura, 1973. 2 v.

PEREIRA, Edithe. A tradição Tupiguarani na Amazônia - um estudo de caso na região de Canaã dos Carajás, PA. Relatório de pesquisa. Belém: Museu Paraense Emílio Goeldi, 2008a.
PEREIRA, Edithe. Arqueologia na região da Serra das Andorinhas. In: GORAYEB, Paulo (Org.). Parque Martírios-Andorinhas: conhecimento, história e preservação. Belém: Universidade Federal do Pará, 2008b. p. 128-153.

PEREIRA, Edithe. Arte rupestre na Amazônia - Pará. São Paulo/ Belém: Unesp/Museu Paraense Emílio Goeldi, 2003.

PEREIRA, Edithe. Registros rupestres e contexto arqueológico na região do baixo/médio Araguaia - setembro/2002. Relatório de pesquisa. Belém: Museu Paraense Emílio Goeldi, 2002a.

PEREIRA, Edithe. Levantamento arqueológico na área da UHEBelo Monte, rio Xingu (PA). Relatório de pesquisa. Belém: Museu Paraense Emílio Goeldi, 2002b.

PEREIRA, Edithe. Salvamento e resgate do sítio Pedra das Arraias, Senador José Porfírio (PA). Relatório de pesquisa. Belém: Museu Paraense Emílio Goeldi. 2000.

PEREIRA, Edithe. Curso Prática em Arqueologia Amazônica. Relatório de Atividades. Belém: Museu Paraense Emílio Goeldi, 1998.

PEREIRA, Edithe. Las pinturas y los grabados rupestres del noroeste de Pará, Amazônia, Brasil, 1996. Tese (Doutorado em Arqueologia e Pré-história) - Universidade de Valencia, Espanha, 1996.

PEREIRA, Edithe; SILVEIRA, Maura Imazio; RODRIGUES, Maria Cristina Leal; COSTA, Cíntia Jalles Carvalho de Araújo; MACHADO, Christiane Lopes. A Tradição Tupiguarani na Amazônia. In: PROUS, André; LIMA, Tânia Andrade (Org.). Os ceramistas Tupiguarani. Belo Horizonte: Sigma, 2008a. v. 1, p. 49-66.

PEREIRA, Edithe; FIGUEIREDO, Silvio Lima de; LIMA, Janice; BARBOSA, Carlos Augusto Palheta; MARTINS, Vitor Nazareno da Mata Martins; ANDRADE, Marcela Nogueira. Pacoval do Curuá arqueologia, educação e turismo no interior da Amazônia. Relatório de pesquisa. Belém: Museu Paraense Emílio Goeldi, 2008b.

PEREIRA, Edithe; FIGUEIREDO, Silvio L. Arqueologia e Turismo na Amazônia: problemas e perspectivas. Cadernos do LEPAARQ - textos de Arqueologia, Antropologia e Patrimônio, v. 2, n. 3 , p. 21-36, 2005.

PEREIRA, Edithe; GUAPINDAIA, Vera Lúcia Calandrini. Levantamento arqueológico em Porto de Moz (PA). Relatório técnico. Belém: Museu Paraense Emílio Goeldi, 1999a.

PEREIRA, Edithe; GUAPINDAIA, Vera Lúcia Calandrini. Levantamento Arqueológico na área da Pequena Central Hidroelétrica Salto Cafesoca, Rio Oiapoque (Amapá). Relatório técnico. Belém: Museu Paraense Emílio Goeldi, 1999b.

PEREIRA, Edithe; KERN, Dirse C.: VERÍSSIMO, César U. Vieira. Nota sobre o salvamento arqueológico do Sitio AP-MA-3: Pacoval - Macapá (Ap). Revista do Centro de Estudos e Pesquisas Arqueológicas, v. 5, p. 55-67, 1986. 
QUEIRÓZ, Albérico Nogueira. Contribution à l'étude archéozoologique des vertébrés de cinq sites préhistoriques de trois régions du Brésil, 2001. Tese (Doutorado em Ciências) - Université de Geneve, Geneve, 2001.

RAMOS, Lilyan Fernanda Menezes. Levantamento de arqueologia histórica na Vila de Monsarás: transformações no aspecto urbano e paisagístico da antiga missão religiosa de Caiá - llha do Marajó, 2005. Trabalho de Conclusão de Curso (Licenciatura e Bacharelado em História) - Universidade Federal do Pará, Belém, 2005.

RODRIGUES-CARVALHO, Cláudia. Relatório de análise de remanescentes humanos recuperados no sítio PA-AT-247: Domingos, Canaã dos Carajás (PA). Relatório técnico referente ao componente Antropologia Física. Belém: Museu Paraense Emílio Goeldi, 2005.

ROOSEVELT, Anna Curtenius, Moundbuilders of the Amazon: Geophysical Archaeology on Marajo Island, Brazil. San Diego: Academic Press, 1991.

ROOSEVELT, A. C.; HOUSE, R.; SILVEIRA, M. I.; MARANCA, S.; JOHNSON, R. Eight Millenium Pottery from a Prehistoric Shell Midden in the Brazilian Amazon. Science, v. 254, n. 5038, p. 1621-1624, 1991.

ROOSEVELT, A. C.; LIMA DA COSTA, M.; MACHADO, C. L.; MERCIER, N.; VALLADAS, H.; FEATHERS, J.; BARNETT, W.; SILVEIRA, M. I.; HENDERSON, A.; SILVA, J.; CHERNOFF, B.; REESE, D. S.; HOLMAN, J. A.; TOTH, N.; SCHICK, K. Paleoindian Cave Dwellers in the Amazon: The Peopling of the Americas. Science, v. 272, p. 373-384, 1996.

ROSA, Cássia Santos da. Contribuição para a História e Arqueologia da Amazônia: Um estudo histórico e arqueológico das coleções Townsend e Frederico Barata do Museu Paraense Emílio Goeldi (1950-1960), 2004. Trabalho de Conclusão de Curso (Licenciatura em História) - Universidade Federal do Pará, Belém, 2004.

ROSA, Cássia Santos da. Um estudo atual das coleções arqueológicas tapajônicas: análise e descrição das Coleções Townsend e Frederico Barata. Relatório Final PIBIC. Belém: Museu Paraense Emílio Goeldi, 2003.

RUIVO, Maria de Lourdes; OLIVEIRA, Rita Denise; LOPES, Paulo Roberto do Canto. Morfologia e micromorfologia de alguns solos antrópicos na região das Ilhas, Belém-PA. In: SIMPÓSIO DE GEOLOGIA DA AMAZÔNIA, 9., 2006, Belém. Anais... Belém: Sociedade Brasileira de Geologia, 2006.

SABÁ, K. L. A. Levantamento bioantropológico de uma população amazônica pré-histórica (Maracá, AP), 2000. Trabalho de Conclusão de Curso (Bacharelado em Ciências Biológicas) Universidade Federal do Pará, Belém, 2000.

SANJAD, Nelson Rodrigues. A Coruja de Minerva - O Museu Paraense entre o império e a República, 1866-1907, 2005. Tese (Doutorado em História das Ciências e da Saúde) - Fundação Oswaldo Cruz, Rio de Janeiro, 2005.
SANTOS, Andréa Kely R.; SANTOS, Sidney E. B.; GUAPINDAIA, Vera Lúcia Calandrini; MACHADO, Ana Lúcia da Costa; ZAGO, M. A. Heterogeneity of Mitochondrial DNA in Pre-Columbian Natives of Amazon Region. American Journal of Physical Anthropology, v. 101, p. 29-37, 1996.

SCHAAN, Denise Pahl. Diagnóstico do Patrimônio Arqueológico na Área de Influência da Rodovia BR-163-Trecho: Santarém-Rurópolis. Relatório técnico. Belém: Museu Paraense Emílio Goeldi, 2006.

SCHAAN, Denise Pahl. La céramique des fêtes, rites et funérailles: le symbolisme sacré de l'art marajoara. In: Brésil Indien: les arts des amérindiens du Brésil. Paris: Réunion des Musées Nationaux, 2005a. p. 161-170.

SCHAAN, Denise Pahl. Origens e Significado da Cultura Marajoara. In: Motivos Ornamentais da Cerâmica Marajoara. 3. ed. Belém: Edições O Museu do Marajó, 2005b. p. 21-29.

SCHAAN, Denise Pahl. Os Geoglifos e a Implantação pela Eletronorte do Sistema de Transmissão do Acre In: Geoglifos da Amazônia: Perspectiva Aérea. 2. ed. Brasília: Eletronorte, 2005c.

SCHAAN, Denise Pahl. The Camutins Chiefdom: Rise and Development of Social Complexity on Marajo Island, 2004. Tese (Doutorado em Antropologia Social) - Universidade de Pittsburgh, EUA, 2004.

SCHAAN, Denise Pahl. A ceramista, seu pote e sua tanga: identidade e papéis sociais em um cacicado marajoara. Revista de arqueologia, v. 16, p. 31-45, 2003.

SCHAAN, Denise Pahl. Estatuetas Antropomorfas Marajoara: $O$ Simbolismo de Identidades de Gênero em uma Sociedade Complexa Amazônica. Boletim do Museu Paraense Emílio Goeldi, série Antropologia, v. 17, n. 2, p. 437-477, 2001 a.

SCHAAN, Denise Pahl. Os Dados Inéditos do Projeto Marajó (1962-1965). Revista do Museu de Arqueologia e Etnologia, v. 11, p. 141-164, 2001b.

SCHAAN, Denise Pahl. Into the Labyrinths of Marajoara Pottery: Status and Cultural Identity in an Amazonian Complex Society. In: Unknown Amazon. Nature and Culture in Ancient Brazil. Londres: The British Museum Press, 2001c. p. 108-133.

SCHAAN, Denise Pahl. Recent Investigations on Marajoara Culture, Marajo Island, Brazil. Antiquity, v. 74, p. 469-470, 2000a.

SCHAAN, Denise Pahl. Evidências para a permanência da cultura marajoara à época do contato europeu. Revista de Arqueología, n. 12/13, p. 23-42, 2000b.

SCHAAN, Denise Pahl; PLENS, Cláudia R. Diagnóstico sobre a Situação do Patrimônio Arqueológico na Área de Implantação das Linhas de Transmissão LT 138 kV Epitaciolância/ Rio Branco e LT 69 kV Rio Branco/Sena Madureira (incluindo áreas das subestações). Relatório técnico. Belém: Museu Paraense Emílio Goeldi, 2005. 
SCHAAN, Denise Pahl; SILVA, Wagner Fernando V. BR-230 Transamazônica: Trecho Altamira - Medicilândia, BR-422: Novo Repartimento-Tucuruí. Relatório técnico. Belém: Museu Paraense Emílio Goeldi, 2005.

SILVA, Francisco José Oliveira da. Pesquisa arqueológica histórica em Santo Antônio de Gurupá: uma análise das mudanças paisagísticas e dos vestígios arquitetônicos remanescentes do final do século XVII, 2002. Trabalho de Conclusão de Curso (Licenciatura e Bacharelado em História) - Universidade Federal do Pará, Belém, 2002.

SILVEIRA, Maura Imazio. Você é o que você come, 2001. Tese (Doutorado em Arqueologia) - Universidade de São Paulo, São Paulo, 2001.

SILVEIRA, Maura Imazio. Estudo sobre estratégias de subsistência de caçadores-coletores pré-históricos do sítio Gruta do Gavião, Carajás (Pará), 1995. Dissertação (Mestrado em Arqueologia) Universidade de São Paulo, São Paulo, 1995.

SILVEIRA, Maura Imazio da; KERN, Dirse Clara; OLIVEIRA, Elisângela Regina de; FRAZAO, Francisco Juvenal L. Seriam as Terras Pretas Arqueológicas grandes áreas contínuas? O caso dos sítios Bitoca 1 e Bitoca 2 na região de Carajás-PA. In: CONGRESSO DA ASSOCIAÇÃO BRASILEIRA DE ESTUDOS DO QUATERNÁRIO, 11., 2007, Belém. Anais... Belém: ABEQUA, 2007.

SILVEIRA, Maura Imazio; SCHAAN, Denise Pahl. Arqueologia (bibliografia). In: SOUZA FILHO, Pedro Walfir M.; CUNHA, Edson R. S. P; SALES, Maria Emília da Cruz; SOUZA, Luiz Fernando M. O.; COSTA, Francisco Ribeiro da (Org.). Bibliografia da Zona Costeira Amazônica Brasil. Belém: Museu Paraense Emílio Goeldi: Universidade Federal do Pará, 2005a. p. 261-264.

SILVEIRA, Maura Imazio, SCHAAN, Denise Pahl. Onde a Amazônia encontra o mar: estudando os sambaquis do Pará. Revista de Arqueologia, n. 18, p. 67-79, 2005b.
SILVEIRA, Maura Imazio; MARQUES, Fernando Luiz Tavares. Levantamento das potencialidades arqueológicas e históricas na área dos municípios de Barcarena e Abaetetuba (PA). Relatório final. Belém: Museu Paraense Emílio Goeldi, 2004.

SIMÕES, Mário Ferreira. Salvamento Arquelógico em Carajás (PA). In: ALMEIDA JR., José Maria Gonçalves (Org.). Carajás: desafio político, ecológico e desenvolvimento. São Paulo: CNPq/ Melhoramentos, 1986. p. 534-559.

SIMÕES, Mario Ferreira. Coletores-pescadores ceramistas do litoral do Salgado (Pará) - Nota preliminar. Boletim do Museu Paraense Emílio Goeldi, Nova Série, Antropologia, v. 78, p. 1-26, 1981 a.

SIMÕES, Mario Ferreira. As pesquisas arqueológicas no Museu Paraense Emílio Goeldi (1870-1981). Acta Amazônica, v. 11, n. 1, p. 149-165, 1981b.

SIMÕES, Mario Ferreira; CORRÊA, Conceição Gentil. Pesquisas arqueológicas na região do Salgado. A fase Areão do litoral de Marapanim. Boletim do Museu Paraense Emílio Goeldi, Nova Série, Antropologia, v. 48, p. 10-30, 1971.

SOEIRO, Milton P.; MOURA, Simone de O.; PAIVA, Zenaide P. Caderno de Educação Patrimonial e Arqueologia. Belém: Museu Paraense Emílio Goeldi, 2008.

SOUZA, Sheila Mendonça. Relatório sobre bioarqueologia de campo e laboratório. Relatório técnico referente ao componente Antropologia Física. Belém: Museu Paraense Emílio Goeldi, 2003.

SOUZA, Sheila Mendonça; GUAPINDAIA, Vera Lúcia Calandrini; CARVALHO, Cláudia Rodrigues. Necrópole Maracá e os problemas interpretativos em um cemitério sem enterramentos. Boletim do Museu Paraense Emílio Goeldi, série Antropologia, v. 17, n. 2, p. 479-520, 2001. 